\title{
Taxa de sobrevivência e desempenho agronômico de melancia sob enxertia
}

\author{
Renata Natália C de S Gamaㅜ; Rita de Cássia S Dias²; Juliana Carla da SF Alves ${ }^{3}$; Léia S Damaceno \\ Fátima A Teixeira ${ }^{3}$; Graziela da $S$ Barbosa ${ }^{4}$ \\ ${ }^{1}$ UEFS-RGV, Av. Transnordestina s/n, Novo Horizonte, 44036-900 Feira de Santana-BA; renata.natalia@hotmail.com; ${ }^{2}$ Embrapa Semi- \\ árido, C. Postal 23, 56302-970 Petrolina-PE; ritadias@cpatsa.embrapa.br; ${ }^{3}$ UNEB, Depto. Ciências Agrárias, C. Postal 171, 48905-680 \\ Juazeiro-BA; juliana_leandro2@yahoo.com.br; leiadama@hotmail.com; fatimateixeira_pe@hotmail.com; ${ }^{4}$ UFC, Depto. Fitotecnia, Av. \\ Mister Hull 2977, Pici, 60021-970 Fortaleza-CE; grazzy26@bol.com.br
}

\begin{abstract}
RESUMO
A enxertia tem sido empregada para conferir resistência às plantas, possibilitando o cultivo em áreas contaminadas por patógenos do solo e quando realizada sobre porta-enxertos apropriados, oferece uma série de vantagens agronômicas em relação ao cultivo convencional. O objetivo desse trabalho foi avaliar a taxa de sobrevivência e o desempenho agronômico e qualitativo da cultivar BRS Opara enxertada por encostia em quatro genótipos de abóbora (Cucurbita moschata): BGC 186, BGC 217, BGC 830 e BGC 830.1; e em dois genótipos de melancia forrageira (Citrullus lanatus var. citroides): BGCIA 223 e BGCIA 857. Quantificou-se a taxa de sobrevivência, em casa de vegetação, sob delineamento experimental inteiramente casualizado; a produtividade das plantas enxertadas e não-enxertadas, bem como os frutos foram caracterizados quanto às seguintes características: formato, coloração externa e interna, massa fresca, firmeza da polpa, sólidos solúveis do centro da polpa e da polpa homogeneizada, acidez titulável, relação sólidos solúveis/ acidez titulável e pH. Para a avaliação agronômica e qualitativa dos frutos adotou-se o delineamento experimental de blocos ao acaso com quatro repetições e parcelas com cinco plantas. A taxa de sobrevivência das mudas enxertadas, após o "desmame", variou em função do porta-enxerto, sendo as melhores taxas observadas em BGC 186 e BGC 830.1. Comparando-se ao rendimento da testemunha $(23,5$ $\mathrm{t} / \mathrm{ha}$ ), houve um incremento médio de $66,5 \%$ na produtividade das plantas enxertadas em BGCIA 223, BGC 830, BGC 217 e BGCIA 857. Para a cultivar BRS Opara, pode-se recomendar inicialmente, estes porta-enxertos que determinaram incremento na produtividade sem afetar a qualidade dos frutos.
\end{abstract}

Palavras-chave: Citrullus lanatus, Cucurbita moschata, enxertia, produtividade.

\section{ABSTRACT \\ Grafted watermelon survival rate and agronomic performance}

Grafting has been used in order to provide resistance to plants, allowing cultivation in areas contaminated by soil pathogens and, when performed on suitable rootstocks, offers a number of agronomic advantages when compared to those obtained with conventional farming. This study aimed to evaluate the survival rate and the agronomic and quality performance of BRS Opara grafted by approach in four genotypes of pumpkin (Cucurbita moschata): BGC 186, BGC 217, BGC 830 and BGC 830.1; and in two genotypes of forage watermelon (Citrullus lanatus variety citroides): BGCIA 223 and BGCIA 857. We quantified the survival rate, in a greenhouse, under a completely randomized design; the grafted and non-grafted productivity and the fruits were characterized by the following parameters: fruit shape, internal and external color, fresh weight, pulp firmness, center pulp soluble solids and pulp homogenized, titratable acidity, ratio of soluble solids to titratable acidity and $\mathrm{pH}$. To evaluate agronomic and qualitative fruit parameters we adopted the randomized block design with four replicates of five plants. The survival rate of grafted seedlings, after weaning, varied depending on the rootstock. Compared to the performance of the control (23.5 $\mathrm{t} \mathrm{ha}^{-1}$ ), there was an average increase of $66.5 \%$ in the productivity of plants grafted on BGCIA 223, BGC 830, BGC 217 and BGCIA 857. For the 'BRS Opara', initially these rootstocks may be recommended, for they have determined increased productivity without affecting fruit quality.

Keywords: Citrullus lanatus, Cucurbita moschata, grafting, productivity.

\section{(Recebido para publicação em 30 de novembro de 2011; aceito em 10 de janeiro de 2013) (Received on November 30, 2011; accepted on January 10, 2013)}

\begin{abstract}
A melancia pertence à família Cucurbitaceae, gênero Citrullus e, tem como centro de origem a África (Mohr, 1986). O Brasil é o quarto maior produtor de melancia. Em 2008 obteve uma produção de 1.950 .000 t/ano, o que contribui para o agronegócio do país com mais de 600 milhões de reais por ano (Agrianual, 2011). O Nordeste
\end{abstract}

brasileiro tem expressiva participação nesse agronegócio. A melancia tem grande importância sócio-econômica, por ser cultivada principalmente por pequenos agricultores, sob condições irrigadas ou de sequeiro, devido ao seu fácil manejo e baixo custo de produção (Dias \& Resende, 2010).

Os patógenos de solo são algumas das dificuldades encontradas no cultivo da melancia. Eles interferem na capacidade das raízes em absorver água e nutrientes. Devido à inexistência de cultivares de melancia resistentes aos principais patógenos do solo, a enxertia em Cucurbita spp. ou em Citrullus spp. pode ser uma alternativa para controle dessas doenças a curto prazo. 
A enxertia tem sido empregada para plantas das famílias Solanaceae e Cucurbitaceae. É uma alternativa para o manejo de plantas em solos com problemas de patógenos, salinidade ou mesmo oscilações de temperatura. Quando realizada sobre porta-enxertos apropriados, oferece uma série de vantagens em relação ao cultivo convencional, como: tolerância a baixas temperaturas, à seca, ao excesso de umidade, aumento da capacidade de absorção de nutrientes, aumento do vigor da planta e prolongamento do período de colheita pois, na maioria das vezes, o porta-enxerto possui sistema radicular mais vigoroso que o da planta enxertada (Oda, 1995; Peil, 2003; Rizzo e al., 2004).

A enxertia na produção comercial de mudas de hortaliças é uma técnica que vem sendo adotada comumente por uma parte significativa dos olericultores em países como Japão, Holanda e Espanha, onde a produção de hortaliças possui caráter mais intensivo (Peil, 2003). Na Espanha, 95\% da melancia cultivada é enxertada sobre um híbrido interespecífico de Cucurbita maxima x Cucurbita moschata, de total afinidade com a melancia, para resolver os problemas de fusariose (Fusarium oxysporum f. sp. niveum), uma vez que a resistência a essa enfermidade em algumas cultivares comerciais não assegurou uma produção normal em solos muito contaminados. Adicionalmente, esse híbrido oferece resistência a Verticilium, tolerância a Pythium e a nematóides, bem como confere mais vigor à planta (Dias et al., 2010).

Goto et al. (2003b), reportando vários autores, afirmam que os métodos tradicionais de enxertia são: fenda simples, encostia, inserção lateral com e sem enraizamento das mudas, contato em bisel, corte horizontal, tubo flexível e adesivo. Oda (1995) e Peil (2003) relataram que o método de encostia é bastante utilizado para Cucurbitáceas. Neste método, durante o processo de cicatrização do enxerto, os dois sistemas radiculares, do enxerto e do porta-enxerto, são mantidos (Peil, 2003) e o índice de sobrevivência é superior ao observado com o método de enxertia por estaca (Nawashiro, 1994).

Há muitos relatos conflitantes sobre as vantagens da enxertia na qualidade dos frutos, tais como aparência do fruto (tamanho, forma, cor e ausência de defeitos e degradação), firmeza, textura, sabor (sólidos solúveis e ácidos), dentre outros (Rouphael et al., 2010). Portanto, é de extrema importância o desenvolvimento de estudos que visem elucidar o efeito de porta-enxertos sob o rendimento e características físico-químicas dos frutos de plantas enxertadas.

Dessa forma, o objetivo deste trabalho foi avaliar a taxa de sobrevivência e o desempenho agronômico e qualitativo da cultivar BRS Opara enxertada por encostia em genótipos de abóbora $(C$. moschata) e em melancia forrageira (Citrullus lanatus var. citroides).

\section{MATERIAL E MÉTODOS}

Os ensaios foram desenvolvidos em casa de vegetação e em campo experimental da Embrapa Semiárido, em Petrolina-PE, (0909'S, 40²2'O, 376 $\mathrm{m}$ de altitude).

Utilizou-se a cv. BRS Opara como enxerto e seis porta-enxertos, sendo quatro acessos de abóbora: BGC 186, BGC 217, BGC 830 e BGC 830.1, pela tolerância a patógenos do solo e dois de melancia forrageira (Citrullus lanatus var. citroides): BGCIA 223 e BGCIA 857 , pela rusticidade e tolerância a períodos prolongados de seca, previamente avaliados. Os acessos pertencem ao Banco Ativo de Germoplasma de Cucurbitáceas (BAG) da Embrapa Semiárido.

Os genótipos de melancia foram semeados em bandejas de poliestireno expandido, com 128 células, contendo substrato comercial para hortaliças Plantmax $^{\circledR}$ e foram mantidos em casa de vegetação. O semeio da abóbora foi cinco dias após a semeadura dos genótipos de melancia, pois aquela apresenta maior velocidade de germinação e de crescimento (Gómez, 1994; Peil, 2003).

Aos doze dias após a semeadura da cv. BRS Opara, a enxertia foi realizada utilizando o método de encostia de acordo com a metodologia descrita por Goto et al. (2003b) com algumas modificações. Eliminou-se a gema terminal da haste principal do porta-enxerto e, em seguida, as mudas foram retiradas das bandejas. Com o auxílio de um bisturi, fez-se a incisão, de mais ou menos $1 \mathrm{~cm}$, no porta-enxerto, em sentido diagonal, de cima para baixo, e de baixo para cima, no enxerto. Para controle fitossanitário preventivo, após a união das mudas, aplicou-se fungicida Metalaxil a $0,3 \%$. As mesmas foram fixadas com filme de PVC ( $2 \mathrm{~cm}$ de largura) na região da enxertia e, imediatamente, transferidas para copos plásticos descartáveis, com pequenos orifícios no fundo dos mesmos, contendo substrato Plantmax ${ }^{\circledR}$.

As mudas enxertas foram distribuídas em bancadas sob delineamento experimental inteiramente casualizado, com 35 repetições para cada combinação cultivar x porta-enxerto. Estas foram mantidas em casa de vegetação à temperatura ambiente e dez dias após a realização da enxertia, efetuou-se o corte do sistema radicular do enxerto (“desmame"), utilizando-se um bisturi. As mudas sobreviventes foram contabilizadas 24 horas após esta prática. As mesmas foram transplantadas para o campo, juntamente com mudas da 'BRS Opara' sem enxertia (SE) como testemunha, adotando-se o delineamento experimental de blocos ao acaso com quatro repetições e parcelas com cinco plantas, no espaçamento de 3,0 x 0,80 m. O manejo cultural (adubação, irrigação, capinas, condução de ramos e tratos fitossanitários) foi o mesmo recomendado para o cultivo convencional de melancia, recomendado por Dias et al. (2010).

Eliminou-se a parte aérea dos porta-enxertos, com uma tesoura para raleio de frutos (Stairless Steel, LIMMAT $\left.610^{\circledR}\right) 20$ dias após o "desmame”. Para a determinação do ponto de colheita dos frutos, observou-se o secamento da gavinha localizada no pedúnculo do próprio fruto, mudança da cor da casca do fruto na região que se mantém em contato com o solo (Dias \& Lima, 2010). A colheita manual dos frutos aconteceu aos 80 dias após a realização da enxertia e foi realizada com auxílio de um canivete, cortando-se o pedúnculo com $5 \mathrm{~cm}$ de comprimento.

Após a colheita, contabilizou-se a produtividade, em seguida os frutos foram levados ao laboratório de melhoramento vegetal da Embrapa Semiárido para avaliação das características forma- 
to; coloração externa e interna; massa fresca (MF): os frutos foram pesados em uma balança digital, estes valores também foram utilizados para estimar a produtividade; firmeza da polpa (FP): determinada com o auxílio do penetrômetro Fruit Pressure Tester, modelo FT 327, da Wagner Instruments, com uma das metades equatoriais do fruto (Pedrosa \& Gurgel, 1999). Os resultados foram obtidos em libras e convertidos para Newton $(\mathrm{N})$ utilizando-se o fator de conversão 4,4482 (Gomes Júnior et al., 2001); sólidos solúveis do centro da polpa (SS) e sólidos solúveis da polpa homogeneizada (SSH): a leitura foi feita com o auxílio de um refratômetro de bancada Abbe Mark II, modelo 10480 da Luca, com correção automática de temperatura (Association of Oficial Agricultural Chemists, 1975), utilizando, o suco extraído do centro do fruto e o da polpa homogeneizada, respectivamente, com o auxílio de uma centrífuga, expressando os resultados em ${ }^{\circ}$ Brix; acidez titulável (AT): foi determinada utilizando $5 \mathrm{~mL}$ de suco homogeneizado diluído em $50 \mathrm{~mL}$ de água destilada e três gotas de fenolftaleína a 1\%. Em seguida, foi realizada titulação com $\mathrm{NaOH}(0,01 \mathrm{~N})$ até o ponto de viragem, previamente padronizado de acordo com a metodologia proposta pelo Instituto Adolfo Lutz (1985); relação sólidos solúveis/acidez titulável (SSH/AT); e pH: determinado por meio de um potenciômetro digital Tecnopon modelo 210p, previamente padronizado em solução tampão com
pH 4,0 e 7,0. As amostras destinadas à avaliação de $\mathrm{pH}$ e de AT foram obtidas da mesma forma que o suco para SSH;

Os dados foram submetidos à análise de variância e as médias comparadas pelo teste de Scott-Knott $(\mathrm{p}<0,05)$, utilizando-se o aplicativo computacional Sisvar 4.0 (Ferreira, 2000).

\section{RESULTADOS E DISCUSSÃO}

Houve diferença significativa na taxa de sobrevivência entre a 'BRS Opara' e os porta-enxertos utilizados (Tabela 1). As melhores taxas de sobrevivência foram obtidas nos porta-enxertos BGC 186 (85\%) e BGC 830.1 (75\%), que foram superiores em $17 \%$ aos demais porta-enxertos. Aumonde et al. (2011b), avaliando as cultivares de melancia 'Congo' e 'Crimson Sweet' enxertadas em porongo (Lagenaria siceraria), abóbora 'Menina Brasileira' (Cucurbita moschata) e na cultivar de abobrinha Sul Mineiro (Cucurbita pepo), obtiveram respectivamente, as seguintes taxas de sobrevivência: para 'Congo' 80\%, 48\% e 20\%; e para 'Crimson Sweet' $78 \%$, $45 \%$ e $22 \%$. O método de enxertia que estes autores utilizaram foi estaca terminal por perfuração apical. Os referidos autores concluíram que o melhor porta-enxerto para a melancia é o porongo, com base apenas na taxa de sobrevivência das mudas enxertadas. Entretanto, no presente trabalho, verificou-se que é possível obter percentagens maiores na taxa de sobrevivência da melancia enxertada em alguns genótipos de abóbora utilizando o método de enxertia por encostia.

A taxa de sobrevivência das mudas enxertadas em melancia forrageira foi de 60 e $65 \%$, números relativamente baixos. Dessa forma, são necessários estudos futuros, onde sejam testados outros métodos de enxertia ou mesmo alguns ajustes no método de enxertia por encostia, a fim de verificar se há possibilidade de aumentar a percentagem da taxa de sobrevivência das mudas enxertadas. Além disso, precisa-se verificar a existência de especificidade entre as cultivares a serem utilizadas como enxerto e porta-enxerto.

A capacidade de uma planta enxertada em outra conseguir com êxito uma união e desenvolver-se como uma planta única, pode ser considerada compatibilidade. Por outro lado, a falta total ou parcial de sobrevivência de mudas enxertadas pode ser atribuída à incompatibilidade. Embora, frequentemente, ocorra uma formação inicial da união satisfatória, às vezes a combinação falha após um tempo. Esta falta total ou parcial de êxito na enxertia ou aparecimento tardio de sintomas com malformação da união, enrolamento das folhas, alteração do hábito de crescimento e/ou da arquitetura da planta, falta de produção, morte da planta em qualquer estádio vegetativo, faz com que se pense em níveis de incompatibilidade (Goto et al., 2003a).

A enxertia é uma prática utilizada

Tabela 1. Taxa de sobrevivência (TS); massa fresca dos frutos (MF), firmeza da polpa (FP), sólidos solúveis do centro da polpa (SS) e da polpa homogeneizada (SSH), acidez titulável (AT), relação sólidos solúveis/acidez titulável (SSH/AT) e pH da melancia 'BRS Opara' sem enxertia (SE) e enxertada em diferentes genótipos (survival rate (TS), fresh weight (MF), pulp firmness (FP), pulp soluble solids center of the pulp (SS) and pulp homogenized (SSH), titratable acidity (AT), ratio of soluble solids to titratable acidity (SS/AT) and pH of fruits of watermelon 'BRS Opara' without grafting (SE) and grafted into different genotypes). Petrolina, Embrapa Semiárido, 2009.

\begin{tabular}{lccrccccc}
\hline Genótipos & TS & $\mathbf{M F}^{*}(\mathbf{k g})$ & $\mathbf{F P}^{*}(\mathbf{N})$ & $\mathbf{S S}^{*}\left({ }^{\circ} \mathbf{B r i x}\right)$ & $\mathbf{S S H}^{*}\left({ }^{\circ} \mathbf{B r i x}\right)$ & $\mathbf{A T}^{*}$ & SSH/AT* & $\mathbf{p H}^{*}$ \\
\hline BGC 186 & $85 \mathrm{a}$ & $7,55 \mathrm{a}$ & $9,82 \mathrm{a}$ & $11,26 \mathrm{a}$ & $9,81 \mathrm{a}$ & $0,13 \mathrm{a}$ & $75,46 \mathrm{a}$ & $5,29 \mathrm{a}$ \\
BGC 217 & $70 \mathrm{~b}$ & $8,97 \mathrm{a}$ & $10,15 \mathrm{a}$ & $11,30 \mathrm{a}$ & $9,17 \mathrm{a}$ & $0,13 \mathrm{a}$ & $70,54 \mathrm{a}$ & $5,23 \mathrm{a}$ \\
BGC 830 & $70 \mathrm{~b}$ & $6,11 \mathrm{a}$ & $9,04 \mathrm{a}$ & $10,86 \mathrm{a}$ & $8,82 \mathrm{a}$ & $0,14 \mathrm{a}$ & $63,00 \mathrm{a}$ & $5,13 \mathrm{a}$ \\
BGC 830.1 & $75 \mathrm{a}$ & $5,90 \mathrm{a}$ & $7,50 \mathrm{a}$ & $11,16 \mathrm{a}$ & $9,04 \mathrm{a}$ & $0,15 \mathrm{a}$ & $60,27 \mathrm{a}$ & $5,18 \mathrm{a}$ \\
BGCIA 857 & $60 \mathrm{~b}$ & $7,72 \mathrm{a}$ & $7,50 \mathrm{a}$ & $11,69 \mathrm{a}$ & $9,25 \mathrm{a}$ & $0,11 \mathrm{a}$ & $84,09 \mathrm{a}$ & $5,37 \mathrm{a}$ \\
BGCIA 223 & $65 \mathrm{~b}$ & $9,11 \mathrm{a}$ & $8,09 \mathrm{a}$ & $11,02 \mathrm{a}$ & $9,14 \mathrm{a}$ & $0,12 \mathrm{a}$ & $76,17 \mathrm{a}$ & $5,34 \mathrm{a}$ \\
Opara (SE) & - & $7,04 \mathrm{a}$ & $7,66 \mathrm{a}$ & $10,91 \mathrm{a}$ & $9,00 \mathrm{a}$ & $0,12 \mathrm{a}$ & $75,00 \mathrm{a}$ & $5,23 \mathrm{a}$ \\
\hline CV(\%) & 32,7 & 26,21 & 20,33 & 5,10 & 4,97 & 9,65 & 10,69 & 1,75 \\
\hline
\end{tabular}

*Médias seguidas pela mesma letra na coluna não diferem significativamente entre si, teste de Scott-Knott, $\mathrm{p}<0,05$ (means followed by the same letter in the column did not differ significantly from each other, Scott-Knott test, $\mathrm{p}<0,05$ ). 


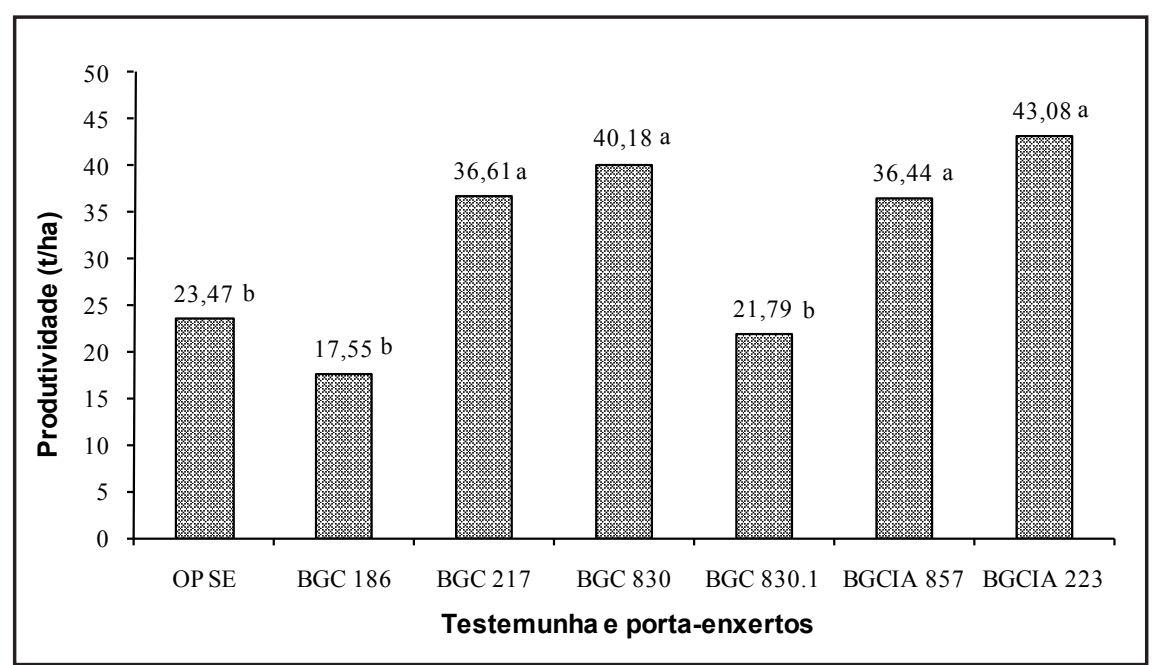

Figura 1. Estimativa de produtividade de BRS Opara sem enxertia (SE) e enxertada em diferentes genótipos: BGC 186, BGC 217, BGC 830, BGC 830.1, BGCIA 857 e BGCIA 223 (productivity of the BRS Opara without grafting (SE) and grafted into different genotypes: BGC 186, BGC 217, BGC 830, BGC 830.1, BGCIA 857 and BGCIA 223). Petrolina, Embrapa Semiárido, 2009.

*Médias seguidas pela mesma letra não diferem significativamente entre si, teste de ScottKnott, $\mathrm{p}<0,05$ (means followed by the same letter did not differ significantly from each other, Scott-Knott test, $\mathrm{p}<0,05)$.

não só para o controle de patógenos do solo, mas também para tolerância às condições desfavoráveis, como temperatura e umidade elevadas, bem como para condições de temperatura mais baixas. Para isso, são utilizados porta-enxertos visando a viabilidade da produção e o aumento da produtividade (Oda, 1995). Comparando-se o rendimento da cv. BRS Opara sem enxertia (23,5 t/ha) houve um aumento médio de $66,5 \%$ na produtividade das plantas enxertadas nos porta-enxertos BGCIA 223, BGC 830, BGC 217 e BGCIA 857 (Figura 1). Entretanto, cv. BRS Opara enxertada em BGC 186 e BGC 830.1, apesar de apresentarem as maiores taxas de sobrevivência após o desmame, obtiveram os menores rendimentos, não diferindo da testemunha (Figura 1). Estes resultados diferem dos encontrados por Aumonde et al. (2011a), que obtiveram em melancia 'Mini Smile' enxertada em seis acessos Cucurbita moschata, Luffa cilyndrica e Lagenaria siceraria, menor rendimento do que as não enxertadas. Provavelmente, os porta-enxertos utilizados no presente trabalho e que revelaram os melhores rendimentos podem ter maior especificidade com a cultivar testada.

Quanto à caracterização dos frutos,
(Yetisir et al., 2003), e C. maxima $\mathrm{x}$ C. moschata ('RS841' e 'Shintoza Camelforce') (Huitrón-Ramírez et al., 2009) foram mais firmes em $24 \%$ e $27 \%$, respectivamente, que os frutos das testemunhas, independente do porta-enxerto, cultivar e condições de crescimento.

Os sólidos solúveis do centro da polpa do fruto variaram de $10,9^{\circ} \mathrm{Brix}$ a $11,7^{\circ}$ Brix, embora não tenha havido diferenças significativas (Tabela 1). Estes resultados estão acima dos valores aceitáveis para melancia (10 $\left.{ }^{\circ} \mathrm{Brix}\right)$ no mercado (Chitarra \& Chitarra, 2005). No entanto, há variações em sólidos solúveis entre as diferentes regiões do fruto, bem como entre distintas cultivares de melancia (Showalter, 1975). Dessa forma, os sólidos solúveis da polpa homogeneizada foram menores quando comparados aos sólidos solúveis do centro da polpa e variaram entre 8,8 ${ }^{\circ}$ Brix e $9,8^{\circ}$ Brix (Tabela 1). Miguel et al. (2004) e Huitrón-Ramírez et al. (2009) também não verificaram diferenças para os sólidos solúveis entre as plantas de melancia enxertadas e não-enxertadas. Por outro lado, Yeitizir et al. (2003) verificaram uma diminuição significativa nos sólidos solúveis da melancia 'Crimson Tide', quando enxertada em C. máxima e C. moschata.

Quanto à acidez, houve variação de 0,11 a 0,15 , que são comparáveis aos encontrados por Almeida et al. (2010) em melancia 'Quetzali' $(0,12)$, sem enxertia; A relação SS/AT é uma das melhores características para avaliar a qualidade das frutas, por ser um importante indicativo do sabor ao relacionar os açúcares e os ácidos da fruta (Chitarra \& Chitarra, 2005). Os valores elevados de SSH/AT obtidos neste trabalho são desejáveis para o mercado de frutas frescas, pois o consumidor brasileiro tem tendência a preferir frutos mais doces e menos ácidos (Tabela 1). Durante o período de maturação, a relação SS/AT tende a aumentar, devido à diminuição dos ácidos e incremento dos açúcares, sendo que o valor absoluto depende da cultivar utilizada (Fachinello et al., 2010).

Com relação ao $\mathrm{pH}$, verificou-se variação entre 5,13 e 5,37, para esta característica. Também não se verificou diferenças significativas entre a 
testemunha e os frutos da 'BRS Opara' enxertada nos diferentes porta-enxertos utilizados (Tabela 1). Esta característica assim como a acidez, estão associadas ao processo de amadurecimento dos frutos e podem ser utilizadas na determinação do ponto de colheita (Chitarra \& Chitarra, 2005).

Para todas as características de frutos avaliadas (formato, coloração interna e externa, massa fresca, FP, SS, SSH, AT, SSH/AT e pH), verificou-se que os porta-enxertos utilizados não determinaram diferenças estatísticas, indicando que os mesmos não afetaram a qualidade dos frutos de 'BRS Opara'. Contudo Aumonde et al. (2011a) verificaram que o híbrido de melancia 'Mini Smile' sob enxertia proporcionou melhores resultados em relação à espessura da casca, coloração da polpa e fenóis totais. Kabori \& Santos (2003), reportando vários autores, observaram redução na qualidade dos frutos, mudança na firmeza, cor e conteúdo de sólidos solúveis da polpa, bem como na coloração da casca, o que não foi verificado no presente ensaio. Assim, fica evidente o efeito da especificidade entre enxerto e porta-enxerto e a necessidade de avaliação de ensaios específicos para as principais cultivares utilizadas no setor produtivo.

Portanto, com base nos resultados obtidos, pode-se recomendar para a cultivar BRS Opara os porta-enxertos BGC 830, BGC 217, BGCIA 223 e BGCIA 857, que determinaram incremento na produtividade sem afetar a qualidade dos frutos. No entanto, necessita-se testar outros métodos de enxertia ou mesmo fazer alguns ajustes no método de enxertia por encostia a fim de conseguir um incremento na taxa de sobrevivência das mudas enxertadas após o "desmame".

\section{REFERÊNCIAS}

AGRIANUAL 2011: Anuário da Agricultura Brasileira. São Paulo: FNP. p. 351-354.

ALMEIDA MALB; SILVA GG; ROCHA RHC; MORAIS PLD; SARMENTO JDA. 2010. Caracterização físico-química de melancia 'Quetzali' durante o desenvolvimento. Revista Caatinga 23: 28-31.

ASSOCIATION OF OFFICIAL ANALYTICAL
CHEMISTS. 1975. Official methods of analysis association of official analytical chemists. Washington: A.O.A.C. 1.094p.

AUMONDE TZ; LOPES NF; PEIL RMN; MORAES DM; PEDÓ T; COGO S; NORA L. 2011a. Enxertia, produção e qualidade de frutos do híbrido de mini melancia Smile. Revista Brasileira de Agrociencia 17: 1-5.

AUMONDE TZ; PEIL RMN; PEDÓ T; STRASSBURGER AS. $2011 \mathrm{~b}$. Compatibilidade e crescimento incial de mudas de melancia enxertadas em diferentes porta-enxertos. Tecnologia \& Ciência Agropecuária 5: 7-11.

CHITARRA MIF; CHITARRA AB. 2005. Póscolheita de frutos e hortaliças: fisiologia e manuseio. Lavras: UFLA. 785p.

DIAS RCS; LIMA MAC. 2010. Colheita e Pós-Colheita. In: DIAS RCS; RESENDE GM; COSTA ND (eds). Sistema de produção de melancia. Disponível em: $<\mathrm{http}$ ://sistemasdeproducao.cnptia.embrapa. br/FontesHTML/Melancia/Sistema ProducaoMelancia/colheita.htm>. Acessado em: 04 maio de 2011

DIAS RCS; RESENDE GM; 2010 . Socioeconomia. In: DIAS RCS; RESENDE GM (eds). Sistema de produção de melancia. Disponível em: <http://sistemasde producao. cnptia.embrapa.br/FontesHTML/Melancia/ SistemaProducaoMelancia/socioeconomia. $\mathrm{htm}>$. Acessado em: 03 de maio de 2011.

DIAS RCS; SOUZA RNC; SOUZA FF; BARBOSA GS; DAMASCENO LS. 2010. Produção de mudas. In: DIAS RCS; RESENDE GM; COSTA ND (eds). Sistema de produção de melancia. Disponível em: <http://sistemasdeproducao.cnptia. embrapa.br/FontesHTML/Melancia/ SistemaProducaoMelancia/producaodemudas. $\mathrm{htm}>$. Acessado em: 03 de maio de 2011.

FACHINELLO JC; NACHTIGAL JC; KERSTEN E. 2010. Fruticultura: fundamentos e práticas. Pelotas: Embrapa Clima Temperado. Disponível em: http://www.cpact. embrapa. br/publicacoes/download/livro/fruticultura fundamentos_pratica/index.htm. Acessado em 20 de setembro de 2011.

FERREIRA DF. 2000. Análises estatísticas por meio do Sisvar para Windows versão 4.0. In: 45를 Reunião Anual da Região Brasileira da Sociedade internacional de Biometria. UFSCar, São Carlos, SP. p.255-258.

GOMES JUNIOR J; MENEZES JB; NUNES GHS; COSTA FB; SOUZA PA. 2001. Qualidade póscolheita do melão tipo Cantaloupe, colhido em dois estádios de maturação. Horticultura Brasileira 19: 223-227.

GÓMEZ AM. 1994. El injerto como método de control de enfermidades del suelo en cucurbitáceas. In: RUIIZ JRD; GARCIAJIMÉNEZ (eds). Enfermidades de las cucurbitáceas en España. Valencia (España): Sociedad Española de Fitopatologia-Phytoma. p. 135-140.

GOTO R; CAÑIZARES KAL; STRIPARI PC. 2003a. Fatores que influenciam a enxertia.
In: GOTO R; SANTOS HS; CAÑIZARES KAL (eds). Enxertia em hortaliças. São Paulo: Editora UNESP. p. 25-32.

GOTO R; KABORI RF; SANTOS HS; CAÑIZARES KAL. 2003b. Metodologia de enxertia. In: GOTO R; SANTOS HS; CAÑIZARES KAL (eds). Enxertia em hortaliças. São Paulo: Editora UNESP. p. 57-67.

HUITRÓN-RAMÍREZ MV; RICÁRDEZSALINAS M; CAMACHO-FERRE F. 2009. Influence of grafted watermelon plant density on yield and quality in soil infested with melon necrotic spot virus. HortScience 44: 1838-1841.

INSTITUTO ADOLFO LUTZ. 1985. Normas analíticas do Instituto Adolfo Lutz: métodos químicos e físicos para análise de alimentos. São Paulo: IMESP. 336p.

KABORI RF; SANTOS HS. 2003. Problemas relacionados ao uso de porta-enxertos na enxertia. In: GOTO R; SANTOS HS; CAÑIZARES KAL. (org). Enxertia em hortaliças. São Paulo: UNESP. p. 33-40.

MIGUEL A; MAROTO JV; BAUTISTA A; BAIXAULI C; CEBOLLA V; PASCUAL B; LÓPEZ S; GUARDIOLA JL. 2004. The grafting of triploid watermelon is an advantageous alternative to soil fumigation by methyl bromide for control of Fusarium wilt. Scientia Horticulturae 103: 9-17.

MOHR HC. 1986. Watermelon breding. In: BASSET MJ. Breeding vegetables crops. Westport: Avi. p. 33-66.

NAWASHIRO T. 1994. Grafting of watermelon. Tsukuba: Tsukuba International Agricultural Training Centre (JICA), 12p. (Apostila, Vegetable Crop Production Course)

ODA M. 1995. New grafting methods for fruit-bearing vegetables in Japan. JARQ 29: 187-194.

PEDROSAJF; GURGELFL. 1999. Adaptabilidade ambiental e estabilidade produtiva em híbridos de melão tipo amarelo. Mossoró: ESAM. 45 p.

PEIL RMNA. 2003. Enxertia na produção de mudas de hortaliças. Ciência Rural 33: 1169-1177.

RIZZO AAN; CHAVES FCM; LAURA VA; GOTO R. 2004. Avaliação de métodos de enxertia e porta-enxertos para melão rendilhado. Horticultura Brasileira 22: 808-810.

ROUPHAEL Y; SCHWARZB D; KRUMBEINB A; COLLA G. 2010. Impact of grafting on product quality of fruit vegetables. Scientia Horticulturae 127: 172-179.

SAMS CE. 1999. Preharvest factors affecting postharvest texture. Postharvest Biol. Technol. 15: 249-254.

SHOWALTER RK. 1975. Sampling watermelons for soluble solids. Florida State Horticultural Society 88: 272-276.

YETISIR H; SARI N; YÜCEL S. 2003. Rootstock resistance to Fusarium wilt and effect on watermelon fruit yield and quality. Phytoparasitica 31: 163-169. 